\title{
ФОРМИРОВАНИЕ НОВОЙ МОДЕЛИ ТРУДА И ЗАНЯТОСТИ НА ЦИФРОВОЙ ПЛАТФОРМЕННОЙ ОСНОВЕ (КОНЦЕПТУАЛЬНЫЙ АСПЕКТ)
}

\author{
(c) 2020 Волков Денис Владимирович \\ управляющий директор 000 «А-Л»
}

В статье утверждается, что складывающаяся в России новая модель труда и занятости изменяет характер труда и его содержание, что вызывает необходимость создания особой цифровой платформы, т.е. насыщенного интеллектуальными компонентами управленческого механизма, наделяемого способностью прогнозировать (планировать) использование трудовых ресурсов. Делается вывод, что движущей силой всех цифровых модификаций является управление Большими данными (Big data), а, следовательно, в образовательные программы ВУЗов следует заложить подготовку управленцев и команд СІО-менеджеров, а также специалистов других многочисленных цифровых профессий.

Ключевые слова: Модель труда, занятость, концепция, проект, цифровая платформа, цифровые технологии, платформенные решения, программно-аппаратный комплекс, рынок образовательных технологий.

Формирование новой модели труда и занятости, получившей в странах с передовой экономикой название «Работа 4.0», а теперь уже и «5.0», сопровождается расширением границ модернизации, совершенствованием образования, повышением качества трудовых ресурсов, изменениями профиля работников с одновременным возрастанием требований к ним. Труд автоматизируется, технологический процесс исполняется системами компьютики, информатики и ИИ, что требует от работников владения многими компетенциями, важную роль среди которых начинают играть lifelong learning и digital literacy [1].

В России процесс трансформации массового труда и занятости пока еще носит замедленный характер, а в проводимых у нас исследованиях выделяются преимущественно только некоторые «атипичные» формы занятости. Проблеме создания добротной системы целенаправленной трансформации трудовых ресурсов при помощи цифровых технологий пока еще уделяется недостаточное внимание. Исходя из этого, нами предлагается рассмотреть концептуальные особенности проекта «Трудовые ресурсы как платформа» (далее - «ТРкП»), обратив внимание на предпосылки, задачи и направления создания условий для трансформации трудовых ресурсов.

Отметим, что специалисты под цифровой платформой понимают цифровую среду (программно-аппаратный комплекс) с набором функций и сервисов, обеспечивающих потребно-

сти ее пользователя. Обычно платформа используется в качестве основного канала, с помощью которого производители товаров и услуг «находят» друг друга, что позволяет им напрямую, т.е. без каких-либо посредников, алгоритмически осуществлять транзакции или создавать инновационные продукты в современных и традиционных отраслях экономики [2]. Представляется, что ценность цифровой платформы заключается не только в том, что в ней воплощаются, как принято считать, «умные» технологии, а прежде всего в том, что она может быть использована в качестве насыщенного интеллектуального компонентами управленческого механизма, способного планировать действия систем, состояние которых определяется огромной совокупностью количественных и качественных индикаторов.

Несомненно, к таким системам относится и главный ресурс общества - его трудовой ресурс (потенциал). Думается, что проект «ТРкП» должен занять подобающее место в совокупности других важных комплексных общегосударственных функциональных проектов. Необходимость его разработки определяется такими важнейшими документами, как: Указ Президента РФ от 09.05.2017 г. «О стратегии развития информационного общества в РФ на 2017-2030 годы», Программа «Цифровая экономика Российской Федерации», утвержденная Правительством РФ 28.06.2017 г., Паспорт национального проекта «Национальная программа «Цифровая экономика Российской Федерации», Паспорт федераль- 
ного проекта «Кадры для цифровой экономики», Федеральные проекты «Цифровые технологии» и «Цифровое государственное управление», утвержденные Правительством России во исполнение Указа Президента Российской Федерации от 07.05.2018 г. № 204 «О национальных целях и стратегических задачах развития Российской Федерации на период до 2024 года».

Кроме того, проект «ТРкП» решает задачу создания цифровой среды, обеспечивающей потребность управляющего субъекта в использовании новых информационно-компьютерных средств в управлении трудовыми ресурсами и позволяющей оперировать единым массивом данных и алгоритмов управления. В этом случае платформенные решения принимаются на основе следующих ключевых принципов: а) датоцентричности и объективности, состоящих в накоплении в онлайн-режиме объективных данных о трудовых ресурсах как объектах управления и в осуществлении контроля за их состоянием посредством использования технологий «Big Data» и ИИ (искусственного интеллекта) и др.; б) процессного подхода, содержанием которого является «пакетное» осуществление всех государственных функций на базе единой цифровой платформы хранения данных, автоматизации управленческих процессов, аналитики, снижения количества шагов процессов и т.д.; в) гибкости и скорости, позволяющих быстро адаптироваться к изменяющимся пространственным, количественным и качественным изменениям в ресурсах труда.

Создание проекта «ТРкП» определяет возможности цифрового обеспечения и реализации других крупномасштабных и долгосрочных общегосударственных проектов, в частности: a) комплексного использования отдельных природных ресурсов, вовлекаемых в народнохозяйственный оборот на той или иной территории; б) комплексного использования нескольких сопутствующих природных ресурсов, вовлекаемых в хозяйственный оборот одновременно, что предполагает решение внутритерриториальных межотраслевых проблем; в) комплексного развития хозяйства в рамках биоэкономических систем, обеспечивающего взаимосвязь производства и биосферы; г) комплексного развития социо-экономических систем, обеспечивающего расширенное воспроизводство населения и улучшение условий его жизнедеятельности.

Важно отметить, что предлагаемая нами цифровая платформа наделяется мультипликационным (увеличивающим, умножающим) свойством. Его суть состоит в том, что создаваемая в результате реализации данной платформы цифровая среда и соответствующие технологии порождают как бы цепную реакцию и распространяются на государственное регулирование экономики, по всей ее системе, увеличивая эффективность последней в целом. Возникает возможность получить реальную оценку, рассчитать интегральный, системный эффект, учтенный в рамках всей системы использованных природных, финансовых и трудовых ресурсов. Задача эта не простая, но к ее решению общество, оснащенное современными средствами компьютики и информатики, активно приближается.

Как свидетельствует наш анализ, проект «ТРкП» целесообразнее всего строить по логической схеме: «цели-пути-способы-средства». Исходя из содержания «Стратегии развития информационного общества в Российской Федерации на 2017-2030 годы», утвержденной указом Президента России от 9 мая 2017 г. № 203, ее целеполаганием должно стать решение следующих задач:

- развитие человеческого потенциала с учетом таких его индикаторов, как: мотивация деятельности; отношение к труду, дисциплинированность; инициативность, предприимчивость; потребности и интересы; способы поведения в тех или иных производственных ситуациях;

- формирование информационного пространства, отражающего количественные и качественные характеристики ресурсов труда, как коллективного субъекта общественного производства, имеющего социальную, демографическую, профессиональную и квалификационную структуру;

- использование современных образовательных технологий, в т.ч. дистанционного, электронного обучения при реализации образовательных программ, программ повышения квалификации работников и их переобучения на новые специальности и профессии для качественного совершенствования ресурсов труда;

- формирование системы управления и мониторинга трудовых ресурсов, основанной на современных информационных и коммуникационных возможностях [3].

С учетом высказанных выше констатаций и следует строить так называемое «дерево целей», что предполагает выделение подцелей и их со- 
гласование [4]. Такие подцели определяются в виде задач в области управления трудовыми ресурсами. К ним следует отнести: а)построение механизма стратегического планирования с заложенными в него инструментами обеспечения российской экономики ресурсами труда необходимого количества и качества (он призван стать частью механизма реализации Федерального закона «О стратегическом планировании в РФ» от 28.06.2014 г. № 172-Ф3); б) создание блок-схемы рационального распределения и перераспределения трудовых ресурсов по территории страны, отраслям экономики и сферам приложения труда; в) разработку рекомендаций по сокращению и в конечном итоге ликвидации теневого сектора экономики, а также возвращению в Россию высококвалифицированных специалистов и молодых ученых, работающих в зарубежных фирмах за пределами нашей страны; г) формирование общегосударственного программно-аппаратного комплекса с набором функций и сервисов, обеспечивающих реальный сектор экономики: кадрами специалистов цифрового и экономико-математического профиля, поддержку способных учащихся средних школ и студентов ВУЗов, совершенствующих свои знания, умения и навыки в области цифровых технологий, широкую доступность для населения страны курсов по компетенциям цифровых технологий; подготовка методических материалов по использованию на российских предприятиях успешных отечественных и зарубежных решений повышения производительности труда и распространение лучших таких практик.

Следует отметить, что все без исключения развитые страны формируют экономику, построенную на знаниях. Последние становятся фундаментом прогресса, а научно-технический потенциал, оставаясь стратегическим ресурсом для инноваций, превращается в признак высокоразвитости государства. В этих условиях весьма трудной и ответственной задачей является выбор из возможных альтернатив наилучшего варианта - по конечным результатам, либо на базе ресурсов, а также выбор и оценка альтернатив, тогда когда они есть и в том случае, когда их нет (по отношению к трудовым ресурсам мы имеем дело именно с отсутствием альтернатив тем задачам, которые обозначены выше). Следовательно, проект «Трудовые ресурсы как платформа», впрочем, как и любой другой, можно представить в виде системы матриц, по гори- зонтали которых располагаются исполнительские структуры, а по вертикали-поставленная цель и этапы ее достижения. На основе теории матричного исчисления и с использованием современных ЭВМ, средств компьютики и информатики представляется возможным анализировать и синтезировать состояние трудовых ресурсов, принимать рациональные решения относительно сроков реализации тех или иных задач и необходимых для этого ресурсов. Подобного рода матричный подход, как правило, сопровождается усилением потребности:

- в моделировании ключевых цифровых компетенций (существующих и новых), которым должно будет обучаться трудоспособное население страны или молодые люди, вступающие в трудоспособный возраст;

- в создании персонального профиля компетенций, т.е. своеобразного «паспорта» знаний, умений, навыков;

- в формировании открытого формата профилей компетенций и персональной образовательной траектории развития;

- в совершенствовании программ профессионального образования и создании новых форматов обучения, исходя из потребностей производства в специалистах с новыми цифровыми компетенциями;

- в использовании гибких систем обучения и переобучения, позволяющих своевременно обеспечивать запросы компаний на современную квалифицированную рабочую силу.

Разумеется, осмысливая концепцию проекта «Трудовые ресурсы как платформа», нельзя обойти вниманием сложившиеся вызовы в этой сфере. Так, острая потребность в работниках с цифровыми компетенциями требует создания условий для их ускоренной подготовки с учетом устаревания содержания многих программ уже до окончания обучения тех или иных специалистов. С учетом этого, в рамках Федерального проекта «Кадры для цифровой экономики» предлагается осуществлять пилотирование образовательных программ высшего образования нового типа продолжительностью до 2-х лет (аналог associate’s degree, half-bachelor) не менее чем для 16 специальностей цифровых технологий. Этот проект может быть реализован с участием различных образовательных организаций посредством отдельного нормативного регулирования [5].

Цифровизация российских предприятий, как уже отмечалось, основывается на управлении 
Большими данными, поэтому кадры по работе с данными (Chief Data Officer - CDO) выступают движущей силой всех цифровых модификаций. А значит, в образовательные программы вузов следует заложить подготовку управленцев и команд CDO-менеджеров. В России, как и во многих других странах, рынок образовательных программ по новым технологиям становится одним из самых перспективных. Примечательно, что общий размер мирового рынка образования составляет примерно 6 трлн. долларов в год. В 2017 году сегмент онлайн образования достиг 165 млрд. долларов и продолжает расти преимущественно за счет стран азиатского региона (Китай, Индия): а также стран Латинской Америки. По мнению экспертов, к концу 2020 года на долю активно развивающихся стран будет приходиться уже 54\% рынка образовательных технологий.

Отечественный рынок образовательных цифровых технологий пока еще только начинает формироваться. По состоянию не начало 2018 года он в денежном выражении составлял примерно 21 млрд. рублей (0,3 млрд. долларов) при общем его объеме 1,8 трлн. рублей (29 млрд. долларов). С учетом того, что если в мире коэффициент освоения онлайн технологий составляет примерно 3\% в год, то при самых оптимистичных расчетах российский рынок новых технологий в образовании сможет вырасти только до 70 млрд. рублей (1,1 млрд. долларов) в год. Отсюда вывод: необходимо государственное регулирование (а не только поддержка) этого процесса, включая стратегическое планирование и создание под патронажем государства венчурного фонда для кредитования и финансирования технических и технологических нововведений, внедрения изобретений и открытий в цифросфере (в т.ч. и для развития системы независимых оценок качества сформированности компетенций цифровой экономики, создания соответствующих образовательных стандартов) [6].

Пока же, по оценкам экспертов, в РФ навыками решения задач в технологически сложной среде ниже 1-го (самого низкого уровня) владеют только 14,9\% населения старше 16 лет, лишь 8,2\% старшеклассников выбирают технические направления из всех тех, по которым организуется профильное обучение в средней школе, только 5,5\% обучающихся в системе дополнительного образования занимаются в технических или спортивно-технических объединениях. В струк- туре российских программ высшего и среднего специального образования, по существу, нет «цифрового компонента» (в развитых странах в ближайшие годы три четверти всех вакансий в сфере STEM, т.е. естественных и компьютерных наук и технологий, а также математики, будет приходиться на цифровую экономику). В сотнях российских университетов продолжается подготовка специалистов, не соответствующая современным мировым стандартам, по устаревшим курсам математики, информатики, компьютерных наук. Это приводит к системному отставанию в тех научных областях, которые обеспечивают подготовку продвинутых специалистов в цифровых технологиях.

Разработка и внедрение проекта «Трудовые ресурсы как платформа» должна осуществляться согласно ГОСТ РИКО 21504-2016 «Управление проектами, программами и портфелем проектов. Руководство по управлению портфелем проектов». В рамках программы (См. ГОСТ Р 54871-2011 «Проектный менеджмент. Требования к управлению программой»), ведется разработка сервисов (по существу, проектирование и внедрение каждого сервиса представляет собой отдельную программу), а также решение соответствующих организационных, нормотворческих и ресурсных задач. При этом целесообразно соблюдать следующие основные исходные положения:

- принцип DevOps (от англ. Development и Operations), т.е. разработки программного обеспечения одной командой программистов, тестировщиков, и администраторов, которая создает, развивает и обслуживает общий для них сервис (продукт) с тем, чтобы организация управляющая ресурсами труда могла эксплуатировать сервис в режиме онлайн и быстро, безболезненно его обновлять;

- принципы Agile, заключающийся в разработке программного обеспечения, ориентированного на использовании интерактивных разработок и постоянном взаимодействии внутри рабочих групп, состоящих из разнопрофильных специалистов. Эти принципы в отличии от классической каскадной методологии (waterfall) создают возможность вовлечь в разработку сервисов их владельцев и потребителей, что особенно важно на этапе прототипирования, где скорость обработки различных вариантов реализации сервисов, напрямую определяет успех цифровой трансформации. 
Нельзя не учитывать, что в современных условиях заметно возрастает роль диджитализации (глубокой трансформации), которая становится главным фактором развития мировой экономики, поскольку конкурентоспособность отдельных стран обусловлена уровнем реализации инновационных технологий как инструмента создания цифровых экосистем [7]. И если первоначально цифровые технологии активно развивались в США, Германии, Японии, то в настоящее время эти страны стали снижать темпы роста технологических (в том числе программно-аппаратных) внедрений и на первый план начинает выходить страны, сумевшие освоить платформенные решения, в первую очередь, в управлении ресурсами (финансовыми, природными и трудовыми).

Учитывая стратегическую важность проекта «Трудовые ресурсы как платформа» представляется необходимым сосредоточить руководство ею в руках Министра экономического развития, подчинив ему организации, непосредственно занимающиеся техническими вопросами. На операционном уровне программу может возглавить Центр электронного правительства, создаваемый в форме публично-правовой компании (См. ФЗ «О публично-правовых компаниях в РФ и о внесении изменений в отдельные законодательные акты РФ» от 3 июля 2016 г. № 236-ФЗ), которому непосредственно подчиняется Программный офис, Центр компетенции, Оператор ГЦП (Оператор), наделяемые соответствующими функциями.

В технологическую часть проекта следует включить базовую архитектуру программноаппаратной составляющей платформы с выделением ее основных технологических и прикладных сервисов, т.е. определить «костяк» платформы, что обеспечит гибкость её развития за счет применения при построении платформы подхода компонентно-сервисноориентированной архитектуры (Microdevice Architecture, MSA). Последний предполагает создание программного приложения, построенного в виде набора сервисов, каждый из которых работает в собственном процессе и коммуницирует с остальными, используя легковесные механизмы. Считается, что основные преимущества MSA состоят в том, что компоненты (микросервисы) платформы: а) быстро вводятся в эксплуатацию; б) устойчивы к сбоям; в) дают возможность использовать разные технологии и разные языки, а это делает смену технологических платформ сравнительно недорогой и не требующей остановки работы всего приложения.

Кроме того, коммуникации между сервисами в самой платформе и другими приложениями предполагают использование OpenAPI (https://www.openapis.org) specification, что позволяет строить интерфейсы между различными программами и хранилищами данных. OpenAPI specification, как известно, поддерживается специализированным фреймворком, что облегчает ее применение производителями программного обеспечения.

В заключение отметим, что создание условий для трансформации трудовых ресурсов позволит достичь прогресса в неоиндустриальном развитии России и включить в экономический оборот имеющиеся у страны технологические заделы (достаточно сказать, что только у трех стран мира - России, КНР и США есть свои технологии беспилотных аппаратов, природных и интеллектуальных ресурсов, которым в современном мире мало кто может что-то противопоставить.

\section{Библиографический список}

1. Сизова И.Л., Хусяинов Т. М. Труд и занятость в цифровой экономике: проблемы российского труда. // Вестник С. Петербургского ун-та., 2017. -Т.10. -С.376-396.

2. Будущее экономики России: роль цифросферы. Вызовы, угрозы, решения. Монография. -М.: ММА, 2018. С.117-121.

3. Луценко С.И. Цифровая трансформация образования в послании Президента Федеральному Собранию 2020. Его же: Единая цифровая платформа как стратегический ресурс государственного управления.

4. Тушов А.А. Целевые программы в системе государственного регулирования экономики // Экономические науки, 2012. -С.151-154.

5. https://digital.gov.ru/uploaded/files/pasport-federalnogo-proekta-kadryi-dlya-tsifrovoj-ekonomiki.pdf 
6. См.: Паспорт Федерального проекта «Кадры для цифровой экономики», Раздел «Дополнительные и обосновывающие материалы». https:/digital.gov.ru/uploaded/files/pasport-federalnogo-proekta-kadryi-dlyatsifrovoj-ekonomiki.pdf

7. Стародубцева Е.Б., Маркова О.М. Цифровая трансформация мировой ээкономики. // Экономика, 2015, № 2. -С.7-15. См.также: Солженцев Е. Д. Цифровая экономика и управление экономикой и государством. // https://topeconomics.ru 